\title{
Innovative Research on College English Teaching in Multi-modal Teaching Mode
}

\author{
Lizhu $\mathrm{Ni}$ \\ Haikou College of Economics, Haikou, Hainan, 571127, China
}

\begin{abstract}
The development of economic globalization has promoted the exchange of culture, politics and science and technology among countries. The relationship between countries has become closer and closer. As a widely used language in the international community, English has become more and more obvious. Cultivating qualified English applied talents is the main tasks of college English teaching. According to this, the author mainly analyzes the current situation of college English teaching under multi - mode teaching mode, and studies its innovative teaching strategies.
\end{abstract}

Keywords: college English teaching; multi - modal model; innovation research

\section{Introduction}

College English teaching is to cultivate students 'ability to use English comprehensively and to promote students' autonomous learning and autonomous inquiry. However, due to the influence of the traditional teaching concept, teachers in the classroom to explain the model is too simple, difficult to mobilize the classroom atmosphere, restricting the development of students thinking of English, teaching effectiveness is not obvious.

\section{The multi-mode teaching analysis}

Multi-modal teaching model is a new teaching model, mainly refers to the use of visual and auditory sensory stimulation and other students to promote access to 
knowledge, make full use of pictures, sounds, language or action to help build symbolic discourse. The traditional English classroom teaching is mainly based on the contents of the textbook teachers will be refined out of knowledge in the classroom display, students can only be based on the idea of teachers to memory, learning. Because English as a foreign language learning, there is no life experience for students, the main existence of understanding and memory difficulties. While the traditional English teaching model is single, students can not feel the unique charm of the English language, learning interest is not high; at the same time in the teacher's explanation, the main meaning is the meaning of words and grammar composition of knowledge, which for college students, the main memory Method is to record and recite, the students side of the record side of the understanding, as one can not use, for their own questions and views are also difficult to reflect to the teacher, the initiative of students to learn is limited. Multi-modal teaching mode is to solve these problems effectively. Multi-modal teaching advocates using multiple data indexes to evaluate teaching results and learning results before, during and after teaching, and advocates teaching materials, teaching methods and teaching investigation.

\section{The status of college English teaching}

\subsection{The teaching concept is backward, teaching approach is single}

In the examination-oriented education background, the pressure and motivation of students are from the college entrance examination, so in high school, students have to pay 12 points to study the various courses, English as the number of three "main" In particular, students spend more time and effort to learn, students of English level is also achieved by leaps and bounds in this period. College teachers in English learning requirements for students also stopped at CET fortysix, in college English teaching, teachers in accordance with the established content on the textbooks to lead students to listen to the tape read through again, do some examples of knowledge points to explain, basically Teaching tasks to complete more than half.

\subsection{The teaching assessment is lagging behind and the students' learning is passive}

In college English teaching, students enter a new learning stage, learning thinking and learning level should have a huge change, but because of college English examination index is still papers and scores, and secondary school is no different, leading to student learning Concept is difficult to change in time, learning is also more passive. However, the school does not understand and implement the requirements of the new curriculum standards - focusing on the cultivation of students 'comprehensive quality and the improvement of the students' professional level, which is the requirement of the syllabus and the teaching task of the students. For the comprehensive study of English subjects in college or in 
the form of papers and scores, students as a result of credit pressure, interest in learning is not high, learning initiative is constrained. Therefore, in the college English teaching assessment mode, it is necessary to actively change the traditional concept of backwardness, innovative methods, enrich the students English assessment elements, improve the comprehensive utilization of English students to promote students' initiative learning and innovative inquiry learning. College English teaching concepts and patterns should keep pace with the times and enrich their connotations.

\subsection{Lack the interaction and motivation to learn}

College teaching advocates independent learning and inquiry learning, but because students are the main learning place is the classroom, the need to learn the object is the teacher and textbooks, access to knowledge exchange the amount of less interactive channels, but not enough suitable opportunity to accept your professional guidance And training, resulting in decreased learning efficiency. English as a language subject, students need to use the economy after the study to the real life, improve their oral English ability to listen to and listen to English listening and speaking skills, learning skills, Reading ability. Students lack communication, the exchange of objects, will weaken the communication, cooperation, it is difficult to improve the motivation and motivation of English learning. Teachers in the teaching of English have not emphasized the importance of autonomous learning and innovative inquiry learning. Students only passively accept the teacher's knowledge in the classroom, do not develop the habit of independent thinking and lack the spirit of academic questioning. [4]

\subsection{Adapt to the needs of the Internet age.}

With the rapid development of modern science and technology, computer screen, animation images will become the main communication media, now almost a staff of the mobile phone students, the use of mobile phones and the use of software more and more perfect, such as proper dictionary, English magic show, these software can help students English word query and oral training. At the same time the rapid development of network technology, a variety of network resources for college students to provide a platform for English learning

\section{The innovation of college English in multi-mode teaching mode}

\subsection{Enrich the teaching content}

College English teaching advocates the improvement of students' comprehensive English and the proficient application of English skills. In daily teaching, teachers should help students to get out of the single classroom teaching mode in middle school, and add more rich elements to English classroom teaching. 
In college English classroom practice, the teacher can design the context according to the content of the textbook, and encourage students to actively participate in the role-playing in the form of classroom interaction, and promote their own oral English training and listening comprehension. For example, the use of more teaching materials in college English version of the book "University Experience English" in the second volume of a unit is on the "Calamities and Rescues", according to the content of this module the teacher can let students in the form of scenarios to start teaching. Such as the introduction of the unit tells the cause of the earthquake, and describes the terrible scene of the earthquake, for these, the teacher can slide show, the text mentioned in the fracture zone, housing collapse and bridge destroyed images display, to enhance the impression of the students; also arranged for students to discuss and enumerate the possible prevention and rescue methods, the other side of the arrangements for several students were demonstrated this treatment.

\subsection{Activities and expand training}

It is not only the knowledge of the textbooks, but also the methods and techniques of English learning which the teacher imparts to the students in the classroom, which is the cultivation of their innovative ability and practical ability. After the completion of classroom teaching, the teacher should also actively encourage and organize a variety of forms of activities, so that students participate in, develop their own English communication skills.

The most visible form of university activity is the community. Students' associations are established on the basis of voluntary organization and voluntary participation. Students are free to participate in various social organizations such as literary societies, English associations, dance societies, schools and teachers according to their interests and interests. We should attach importance to the role played by student associations, encourage students to interact and cooperate. In college English teaching, teachers can participate in the community, and actively encourage students to English poetry, English speech and English drama performances and other activities.

\subsection{Update the teaching materials}

The multi - modal teaching mode of English mode mainly refers to the English teaching in all aspects of the full mobilization of the outside world is conducive to teaching, is conducive to learning and effective factors, add teaching support materials and auxiliary means to achieve diversified teaching, improve student learning efficiency. On the College English Teaching Materials Selection on the school should be done in a timely manner.

Compilation of teaching materials can be combined with other colleges and universities on the basis of field research according to the learning situation of students and international foreign language requirements for the rich textbook content. For example, you can increase the number of foreign customs, folk culture and international exchanges in the article. On the one hand can broaden the horizons of students, so that students with a more objective and 
comprehensive view of different national cultures, and respect for cultural differences on the basis of the development of targeted learning strategies; the other hand, the students of national events and international situation Understanding, and strengthen the sense of responsibility and social responsibility of students, students develop an open and impartial manner to understand the analysis of the problem.

\subsection{The teaching with information technology}

With the continuous improvement of social and economic level, the rapid development of science and technology, advanced technology and equipment widely used in people's lives, work and study for people to bring great convenience. In this era of great development of information technology, schools and teachers should actively use modern technical means to start teaching.

Make full use of multimedia teaching model. PPT is not only to replace the blackboard of a classroom content display, but in the teaching using voice, image, language and other means of action and students in the classroom for effective interaction. Multimedia courseware design is very important, teachers in the production process of multimedia courseware not only to consider how to more effectively carry out the dissemination of knowledge, but also should consider how to stimulate students' creativity and self-learning ability.

But also can use the multimedia means to establish English learning platform. For example, you can set up English learning groups in class, English salon, etc., regular keynote speech and discussion. You can also use the QQ group to establish English conversation group, teachers and students in the group to communicate with each other, ask each other questions and answers FAQ

English as an important international language, and the gap between China's traditional culture, students do not have the influence of the language environment and no professional and technical personnel of the field guidance, learning conditions are limited. However, in the development of Internet technology today, teachers can use multimedia teaching to enrich students' foreign language knowledge and inject new vitality into classroom teaching. At the same time students can also use the Internet resources to find learning materials, you can use the remote teaching along with the teacher to ask questions, finished the evening course teaching. It is difficult for students to learn unfamiliar foreign language culture. At the same time, students are curious about novelty. By using this method, the teacher can use Internet multimedia technology to meet the students' learning needs in innovative ways and means of classroom teaching. At the same time, college teachers should also strengthen their own multimedia technology and Internet technology application exercise for the practical application of English teaching technology to lay the foundation to achieve information technology teaching. 


\section{Conclusion:}

College English teaching is to lay a solid foundation for the students 'comprehensive English application ability and English literacy enhancement. Multimodal teaching mode can be innovated in the teaching methods and teaching evaluation to enrich the teaching contents and broaden students' learning channel and comprehensively improve students' English learning ability of selfexploration and communication and cooperation. In the context of multimodal teaching mode, college English teaching also needs to sum up experience and innovation methods in practice, and promote the improvement of English teaching quality and teachers' teaching level.

\section{Acknowledgements}

Hainan Province Education and Teaching Reform Research Project: Research and Practice of Improving English Autonomous Learning Ability of College Students under Multimodal Teaching Environment - Based on Exploring the Use of Library Network Resources(Hnjg2015-64).

\section{References}

[1] Liu Jie, Ma Lili. Application of Multi-modal Teaching Mode in College English Teaching. Science and Education, 55(12), pp.68-70, 2011

[2] Liang Ruifang. Multi-modal teaching mode innovation practice in college English teaching and learning practice. Journal of Chifeng University (Natural Science Edition), 8 (5), pp.87- 91, 2013

[3] Chen Zhengfeng, Yang Yue. Cao Zhi-hong. Study on Dynamic Balance Model of College English Classroom under Multimodal and Multimedia Environment. Journal of Xidian University (Social Sciences), 12(10), pp. 18- 20, 2012

[4] LI Jing. Multi-modal teaching model in college English teaching application research. Tianjin Vocational College Journal, 9(6), pp.58- 61, 2011

[5] Huang Wei. Innovation and Practice of College English Teaching ModelCollege English Teaching Design and Application under Multi-modal, Journal of Jiamusi Vocational College, 8(4), pp.85-87, 2014 